\title{
Efficient organic photovoltaics from soluble discotic liquid crystalline materials
}

\author{
L. Schmidt-Mende ${ }^{\mathrm{a}, *}$, A. Fechtenkötter ${ }^{\mathrm{b}}$, K. Müllen ${ }^{\mathrm{b}}$, R.H. Friend ${ }^{\mathrm{a}}$, J.D. MacKenzie $^{\mathrm{a}}$ \\ ${ }^{a}$ Department of Physics, Cavendish Laboratory, University of Cambridge, Madingley Road, Cambridge, CB3 OHE, UK \\ ${ }^{\mathrm{b}}$ Max-Planck-Institute for Polymer Research, Mainz, Germany
}

\begin{abstract}
Two different types of soluble discotic liquid crystalline materials and a crystalline perylene dye have been used to create, directly from solution, photovoltaic devices which are compared in this work. Self-organisation of the soluble electron-accepting perylene derivative and the soluble liquid crystalline (LC) discotic material which is stable in a LC phase at room temperature $\left(\mathrm{HBC}-\mathrm{PhC}_{12}\right)$ leads to segregated structures optimised for charge separation and transport in photovoltaic device structures. High external quantum efficiencies up to $34 \%$ near $490 \mathrm{~nm}$ have been reached. The high efficiencies result from efficient photo-induced charge transfer between the materials as well as effective transport of electrons and holes to the cathode and anode through segregated perylene and the discotic peri-hexabenzocoronene p-system. Atomic force microscopy and device characteristics suggest that the driving force for phase separation and surface energy effects during spin coating of the $\mathrm{HBC}-\mathrm{PhC}_{12}$ :perylene blend result in a spontaneous vertical segregation of the $\mathrm{HBC}$ and the perylene normal to the plane of the spun film. This represents a nearly ideal, self-organised structure in which vertical segregation of charge transport layers coexist with a high interfacial area between the two charge transfer components. This vertical segregation has not been observed in the spin-coated blends where the $\mathrm{HBC}-\mathrm{PhC}_{12}$ is replaced by $\mathrm{HBC}-\mathrm{C}_{8}^{*}$. One probable reason for this may be the different phase stability of the LC phase in the HBCs, which leads to different film-forming properties and film morphologies.
\end{abstract}

PACS: 73.50.Pz; 73.61.Ph

Keywords: Organic photovoltaics; Discotics; Liquid crystalline; Coronene

\section{Introduction}

In the past significant effort has been directed towards the exploitation of conducting polymers and small molecules in optoelectronic applications like transistors [1,2], light-emitting diodes [3-7] and also photodiodes [8-11]. One of the main motivations for

\footnotetext{
* Corresponding author. Tel.: +44-1223-337-285; fax: +441223-353-397.

E-mail address: 1js38@cam.ac.uk (L. Schmidt-Mende).
}

the ongoing research is the easy and cheap processibility of these materials compared to inorganic semiconductors. The first commercially available products in the form of organic light-emitting diodes will soon be on the market. Although there has been great progress in organic photovoltaic devices, these still have a lower efficiency than conventional inorganic photovoltaic devices. One of the major steps forward in soluble organics was the use of charge-separating blends instead of intrinsic materials [12]. Since then major efforts have been made to study and control 


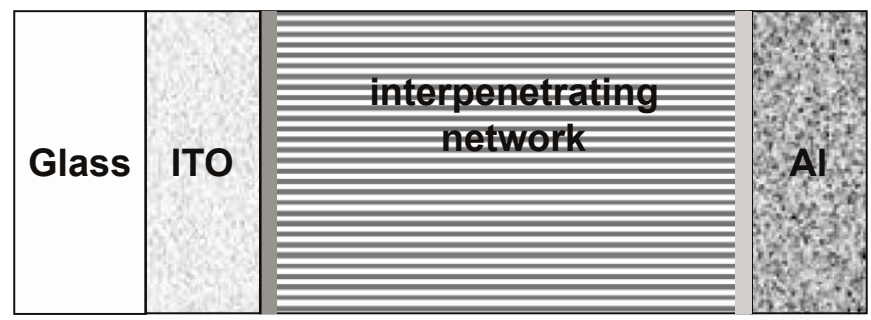

perylene

(a)

HBC

(b)<smiles>CCC(CC)N1C(=O)c2ccc3c4ccc5c6c(ccc(c7ccc(c2c37)C1=O)c64)C(=O)N(C(CC)CC)C5=O</smiles>

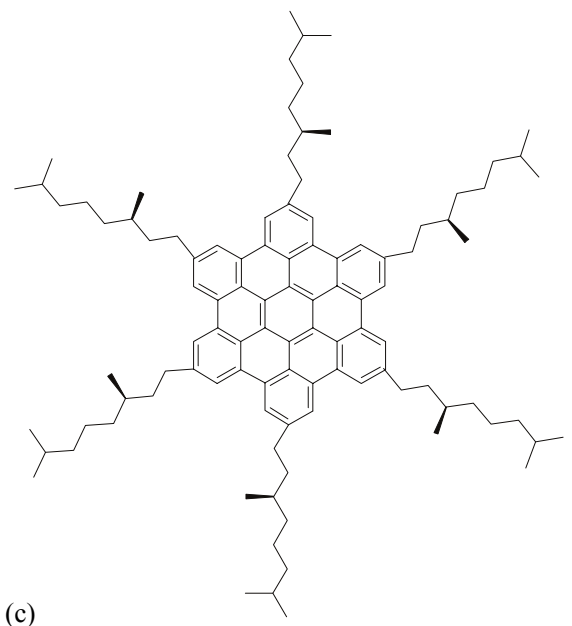

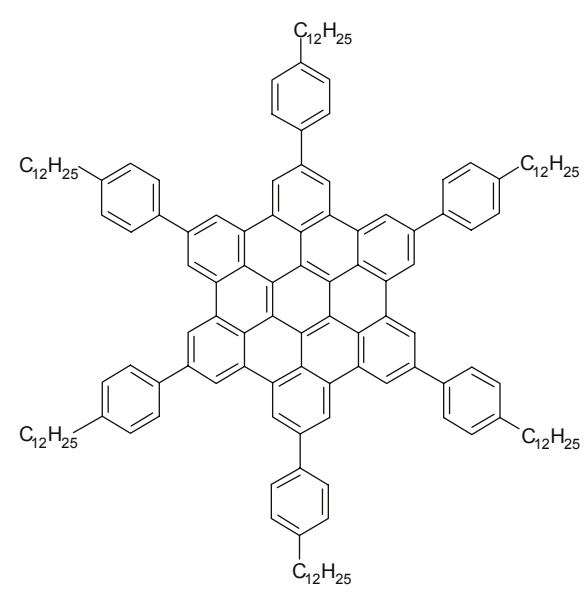

(d)

Fig. 1. Ideal photovoltaic device structure (A) and chemical structure of the perylene derivative (B), HBC-C ${ }_{8}^{*}(C)$ and $\mathrm{HBC}-\mathrm{PhC} 12(\mathrm{D})$.

the morphology of blend devices, because this has been found to be a main issue for device performance $[13,14]$. For an ideal device, we seek an interpenetrating network between an electron-acceptor and -donator material and a gradient in the two materials towards the electrodes so that close to the cathode the film is richer in hole-accepting material and vice versa at the anode (Fig. 1(A)). The phase separation has to be smaller than the diffusion range of created excitons that is usually in order of $10-20 \mathrm{~nm}$ in polymers but significant larger in small molecular organics. Then every exciton could be separated into positive and negative charge and transferred by the different materials to the anode and cathode, respectively. Furthermore it is important, that in the organic semi-conducting film no islands of one or the other material exist, where charge would be trapped. Another related issue is a high charge carrier mobility 
of the organic materials, that ensures, once charge is separated, it will be collected by the electrodes driven by the internal field of the different workfunctions of anode and cathode material.

\section{Results and discussion}

A perylene derivative (Fig. 1(B)), which is known to have high charge mobility, is used as the electron acceptor $[15,16]$. As the hole acceptor, two different kinds of peri-hexabenzocoronene, $\mathrm{HBC}-\mathrm{PhC}_{12}$ and $\mathrm{HBC}-\mathrm{C}_{8}^{*}$ (Fig. 1(C) and (D)), are used $[17,18]$. The photovoltaic devices have been prepared by spin coating the materials from chloroform solution onto an indium-tin-oxide (ITO) coated glass substrate. On top of the film an aluminium electrode was evaporated under vacuum $\left(p<3 \times 10^{-6}\right.$ mbar $)$. All processing steps have been undertaken under nitrogen atmosphere. Device measurements were performed in vacuum ( $p \sim 10^{-5} \mathrm{mbar}$ ). The measurements are not corrected for reflection losses and light absorption in the ITO. Previously the morphology of $\mathrm{HBC}-\mathrm{PhC}_{12}$-perylene blend has been described [19], which seems to have a nearly ideal structure for photovoltaic devices. $\mathrm{HBC}-\mathrm{PhC}_{12}$ is a discotic material, which has a liquid crystalline phase at room temperature. It is known to have a high charge carrier mobility [20]. From crossed polarised microscopy images of $\mathrm{HBC}-\mathrm{PhC}_{12}$ films spin-coated from solution domain structure on a micron scale can be observed. A close study of the blend film morphology shows that the surface of the blend film is completely covered by small perylene crystallites (Fig. 2(B)). Cross-section images indicate a vertically segregated structure, where an $\mathrm{HBC}$ - $\mathrm{PhC}_{12}$-rich phase is underneath the perylene-rich surface of the film (Fig. 2(D)). This spontaneous vertical segregation of the $\mathrm{HBC}-\mathrm{PhC}_{12}$ and the perylene normal to the plane of the spun film forms a nearly ideal structure for photovoltaic devices. It is obtained during spin coating of the $\mathrm{HBC}-\mathrm{PhC}_{12}$ :perylene blend, driven by solubility and surface energy phase-separation effects. This explains the high external quantum efficiencies (EQE) of the device (Fig. 3(A)). In this device a large interfacial area between the $\mathrm{HBC}-\mathrm{PhC}_{12}$ and the perylene can be found. This is important for successful photo-induced charge transfer between the materials, which sepa- rate the charges and avoid recombination processes. One could expect more efficient charge separation in the $\mathrm{HBC}-\mathrm{C}_{8}^{*}$ blends than in the $\mathrm{HBC}-\mathrm{PhC}_{12}$ blends, because of the smaller side chains length of the HBC-C $\mathrm{C}_{8}^{*}$. The perylene-hexabenzocoronene distance is likely to be smaller and, therefore, charge transfer might be favourable. But, at this time other factors inhibit the exploitation of this advantage. By replacing the $\mathrm{HBC}-\mathrm{PhC}_{12}$ with $\mathrm{HBC}-\mathrm{C}_{8}^{*}$, which enters its LC phase over $99^{\circ} \mathrm{C}$, a different film morphology can be observed. AFM images show that a pure film of $\mathrm{HBC}-\mathrm{C}_{8}^{*}$ is non-continuous and has deep holes almost through the entire film (Fig. 2(A)). Blended with perylene, the film is rougher and perylene crystallites can be observed (Fig. 2(C)). Annealing the films at temperatures above the LC phase temperature smoothes the film and improves device performance. In addition the open-circuit voltage increases, which is probably the result of a lower pinhole density. Also, the perylene crystallites observed before annealing are no longer observed on the film surface. A reason for this could be that the $\mathrm{HBC}-\mathrm{C}_{8}^{*}$ is now covering the perylene crystallites and effective vertical segregation is not observed in these films. The rough and somewhat discontinuous films make non-short circuit devices difficult. The measurements shown were taken from devices with films thickness of $\sim 110 \mathrm{~nm}$. Chloroform as a solvent has a low boiling point resulting in a high evaporation rate during fabrication. By spin coating the film from a chloroform solution, the materials have only seconds to arrange themselves before the solvent is evaporated and the film structure is frozen in. $\mathrm{HBC}-\mathrm{PhC}_{12}$ has a greater degree of mobility than $\mathrm{HBC}-\mathrm{C}_{8}^{*}$ because of its liquid crystallinity at room temperature. Also the difference in the side chain length of the HBCs might have an influence on the solubility and film-forming properties. During the film formation process, it is possible that lyotropic LC effects are substantially different for the two HBCs. The EQE is almost a factor of two higher for the $\mathrm{HBC}-\mathrm{PhC}_{12}$-perylene blend devices $\left(\mathrm{EQE}_{\max }=34 \%\right)$ (Fig. $3(\mathrm{~A})$ ). The strong response in particular regions of the action spectra corresponds to the absorption of the perylene and the HBCs. The short-circuit current is a factor of ten higher for the HBC-PhC $12\left(I_{\mathrm{SC}}=33.5 \mu \mathrm{A} / \mathrm{cm}^{2}\right)$ device. Also the open-circuit voltage for these devices $\left(V_{\mathrm{OC}}=0.69 \mathrm{~V}\right)$ is higher. The highest open-circuit 

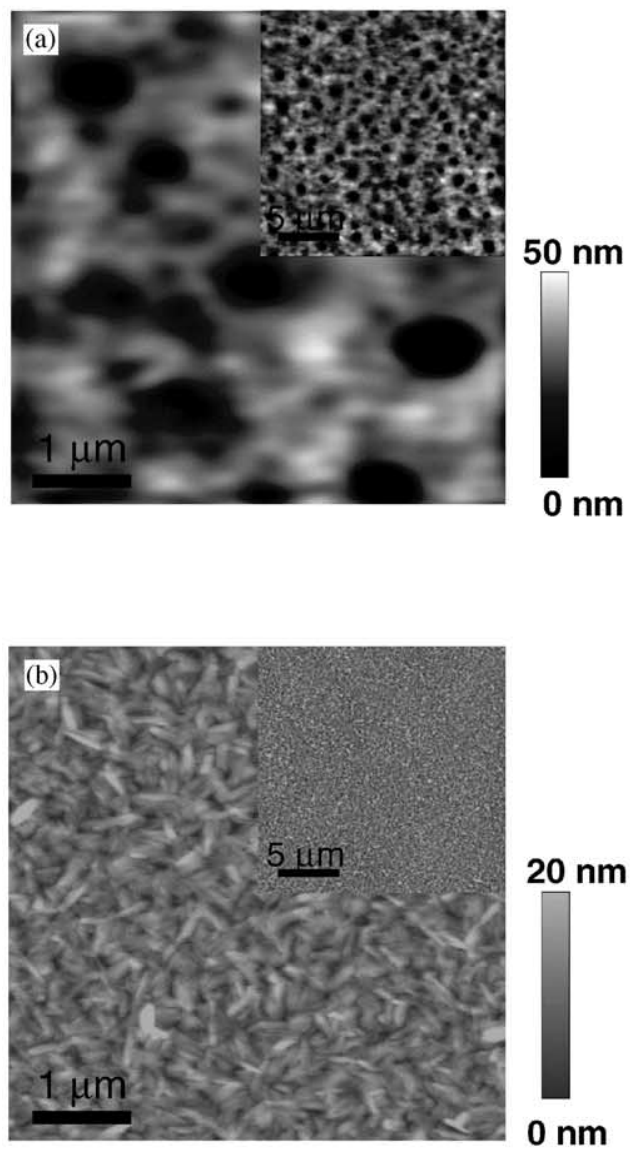
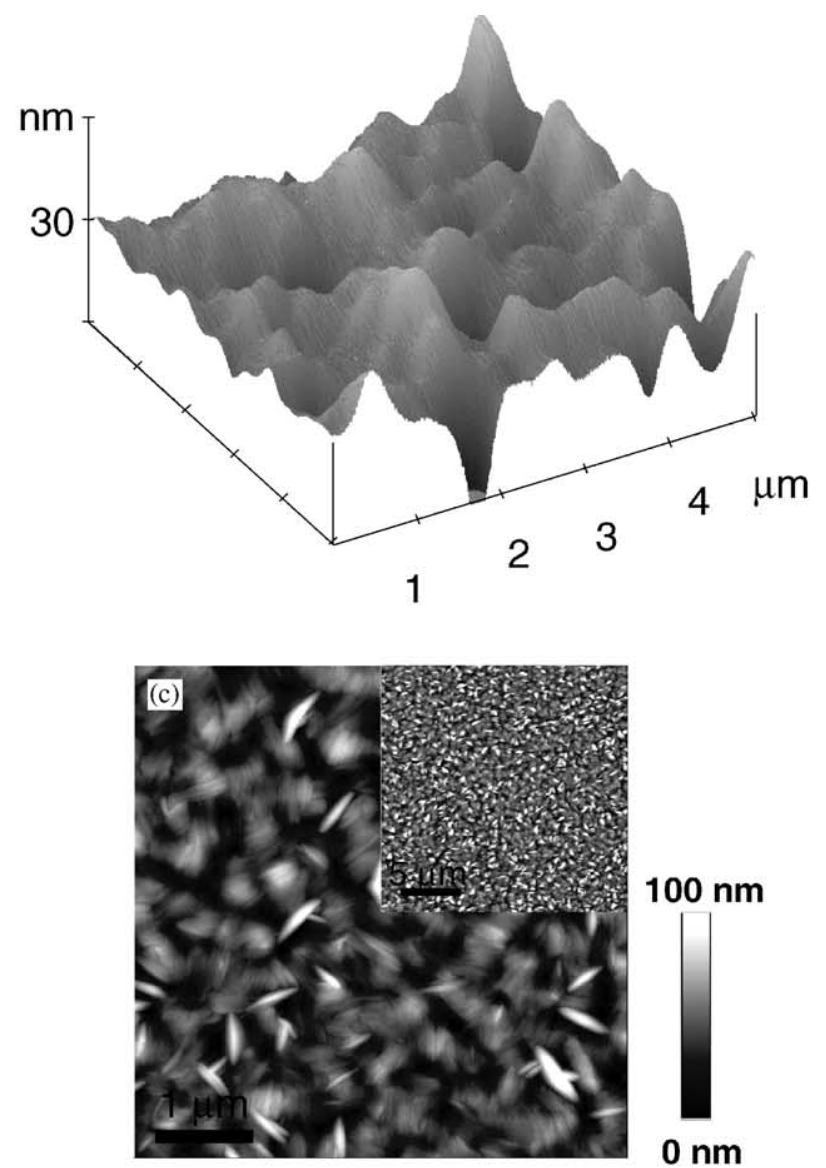

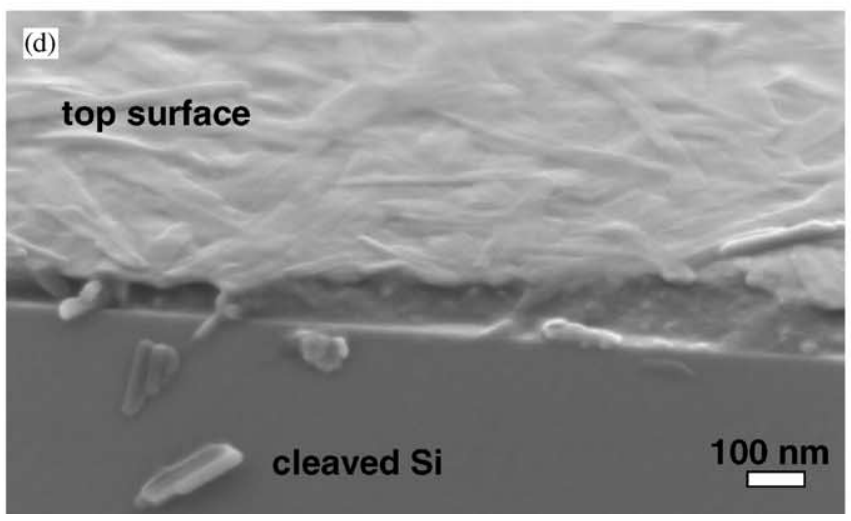

Fig. 2. (A) $5 \times 5 \mu \mathrm{m}$ (inset $20 \times 20 \mu \mathrm{m}$ ) AFM images recorded in tapping mode of a pure $\mathrm{HBC}-\mathrm{C}_{8}^{*}$ film (height image and 3D image); (B) shows the $\mathrm{HBC}-\mathrm{PhC}_{12}$ :perylene (40:60 weight ratio); and (C) the $\mathrm{HBC}_{-} \mathrm{C}_{8}^{*}$ :perylene (same ratio) film; (D) shows a scanning electron micrograph of the cleaved edge of a $\mathrm{HBC}-\mathrm{PhC}_{12}$ :perylene blend film (40:60 weight ratio). 

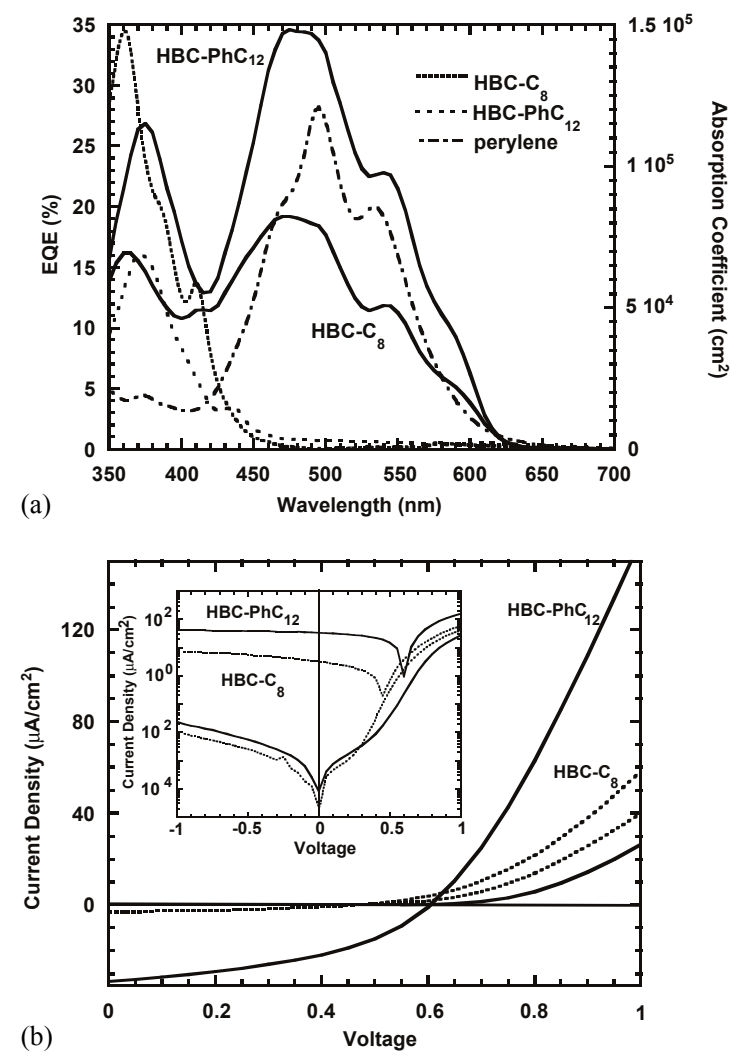

Fig. 3. (A) External quantum efficiency of $\mathrm{HBC}-\mathrm{PhC}_{12}$ :perylene and $\mathrm{HBC}-\mathrm{C}_{8}^{*}$ :perylene devices (solid line) and the absorption coefficients of perylene, $\mathrm{HBC}-\mathrm{PhC}_{12}$ and $\mathrm{HBC}-\mathrm{C}_{8}^{*}$; (B) shows the $I-V$ characteristic of the blend devices $\left(\mathrm{HBC}-\mathrm{PhC}_{12}\right.$ solid line and HBC-C ${ }_{8}^{*}$ dotted line) in the dark and under $490 \mathrm{~nm}$ illumination.

voltage for the $\mathrm{HBC}-\mathrm{C}_{8}^{*}$-perylene devices was $0.46 \mathrm{~V}$ (Fig. 3(B)). An important criterion for photovoltaics is the fill factor $\left(\mathrm{FF}=(I V)_{\max } /\left(I_{\mathrm{SC}} V_{\mathrm{OC}}\right)\right)$. Here also the $\mathrm{HBC}-\mathrm{PhC}_{12}$-perylene devices have a higher value $(\mathrm{FF}=40 \%)$ compared to the $\mathrm{HBC}-\mathrm{C}_{8}^{*}(\mathrm{FF}=32.5 \%)$. These values result in a power efficiency maximum of $\eta=1.95 \%$ and $0.1 \%$ at $490 \mathrm{~nm}$, respectively.

\section{Conclusion}

The higher efficiencies of the $\mathrm{HBC}-\mathrm{PhC}_{12}$-perylene devices compared to the $\mathrm{HBC}-\mathrm{C}_{8}^{*}$ may be a result of the stability of the LC phase of $\mathrm{HBC}-\mathrm{PhC}_{12}$ at room temperature, which might be related to good film-forming properties during room temperature spin coating. Nevertheless the HBC-C $\mathrm{C}_{8}^{*}$ shows a high external quantum efficiency and gives further indication of the promise of $\mathrm{HBC}$ materials for photovoltaic devices. Devices containing $\mathrm{HBC}-\mathrm{C}_{8}^{*}$ are still expected to lead to higher efficiencies than those containing $\mathrm{HBC}-\mathrm{PhC}_{12}$, because of the smaller aliphatic side chains. Lower evaporation rate solvents, that allow the materials more time for self-ordering and possibly better exploit lyotropic effects may improve the efficiencies in $\mathrm{HBC}-\mathrm{C}_{8}^{*}$ devices.

\section{Acknowledgements}

Partial funding was provided by Sony International (Europe) and by the European Union (DISCEL G5RD-CT-2000-00321).

The authors would like to thank Drs. A. Yasuda, G. Nelles and T. Miteva (Sony International) for fruitful discussions. Also we would like to thank A.C. Arias, J.J.M. Halls and C. Ramsdale (Cavendish Laboratory, University of Cambridge) for their help.

\section{References}

[1] H. Sirringhaus, N. Tessler, R.H. Friend, Science 280 (1998) 1741.

[2] H. Sirringhaus, et al., Science 290 (2000) 2123.

[3] J.H. Burroughes, et al., Nature 347 (1990) 539.

[4] Y. Yang, Q. Pei, A.J. Heeger, J. Appl. Phys. 79 (1996) 934.

[5] N. Tessler, N.T. Harrison, R.H. Friend, Adv. Mater. 10 (1998) 64.

[6] R.H. Friend, et al., Nature 397 (1999) 121.

[7] P.K.H. Ho, et al., Nature 404 (2000) 481.

[8] J.J.M. Halls, et al., Nature 376 (1995) 498.

[9] M. Granström, et al., Nature 395 (1998) 257.

[10] J.H. Schön, Ch. Kloc, E. Bucher, B. Batlogg, Nature 403 (2000) 408.

[11] S.E. Shaheen, C.J. Brabec, N.S. Sariciftci, Appl. Phys. Lett. 78 (2001) 841.

[12] C.W. Tang, Appl. Phys. Lett. 48 (1986) 183.

[13] J.M. Halls, et al., Adv. Mater. 12 (2000) 498.

[14] A.C. Arias, et al., Macromolecules 34 (2001) 6005.

[15] J.H. Schön, C. Kloc, B. Batlogg, Appl. Phys. Lett. 77 (2000) 3776.

[16] W.C. Struijk, et al., J. Am. Chem. Soc. 122 (2000) 11057.

[17] A. Fechtenkötter, K. Saalwächter, M.A. Harbison, K. Müllen, H.W. Spiess, Angew. Chem. Int. Ed. 38 (1999) 3039.

[18] A. Fechtenkötter, N. Tchebotareva, M.D. Watson, K. Müllen, Tetrahedron 57 (2001) 3769.

[19] L. Schmidt-Mende, et al., Science 293 (2001) 1119.

[20] A.M. van de Craats, et al., Adv. Mater. 11 (1999) 1469. 